\title{
Correlation between Surgical Outcomes of Primary Hyperparathyroidism with Neck Ultrasound and Parathyroid Scan-Tc99m/MIBI Localization Studies in Dubai Hospital
}

\author{
Budoor Alemadi ${ }^{\mathrm{a}}$ Maryam Ahmad Alsaeed $^{\mathrm{b}}$ Fatima Alsayyah $^{\mathrm{a}} \quad$ Salma Rahma ${ }^{\mathrm{c}}$ \\ Fatheya Al Awadi ${ }^{a}$ Fauzia Rashid ${ }^{\mathrm{a}}$ \\ aDepartment of Endocrinology, Dubai Hospital, Dubai Health Authority, Dubai, United Arab Emirates; \\ ${ }^{b}$ College of Medicine, Mohammed Bin Rashid University of Medicine and Health Sciences, Dubai, United Arab \\ Emirates; ' Department of Medical Education, Dubai Health Authority, Dubai, United Arab Emirates
}

\section{Keywords}

Primary hyperparathyroidism $\cdot$ Parathyroid $\cdot$ Neck

ultrasound · Technetium-99m-sestamibi

\begin{abstract}
Objective: The aim of this study is to assess the correlation between the findings in preoperative localization studies and biochemical parameters with the surgical outcome in patients with primary hyperparathyroidism. Design and Methods: In patients with hyperparathyroidism, preoperative localization imaging studies are considered important for their role in surgical cure, operative length, and extent of surgical incision. Sometimes discordant imaging studies lead to further extensive diagnostic work-up to avoid operative risks and may result in delay to surgical referral. In this single-center retrospective study at a tertiary referral center in Dubai, we evaluated the concordance of presurgical imaging modalities in primary hyperparathyroidism with the surgical outcome after parathyroidectomy. Results: This study included $n=59$ patients. $74.6 \%$ were female, and the mean age was 52.59 years $(S D=13.6)$. Preoperative parathyroid sestamibi scans were done on $n=50$ patients with $68 \%$ having a positive result. A radiology department neck ultra-
\end{abstract}

Karger@karger.com www.karger.com/dde

Karger:

BOPEN ACCESS
(C) 2022 The Author(s)

Published by S. Karger AG, Basel

This is an Open Access article licensed under the Creative Common Attribution-NonCommercial-4.0 International License (CC BY-NC) (http://www.karger.com/Services/OpenAccessLicense), applicable to the online version of the article only. Usage and distribution for commercial purposes requires written permission. sound was done on $n=42$ patients, $52 \%$ of whom had a positive finding for a parathyroid adenoma, while $n=17$ patients required an endocrinology department neck ultrasound scan with $71 \%$ having a positive finding. Complete concordance of findings with the postoperative pathology result was found in $78 \%$ of patients who had a preoperative parathyroid sestamibi, $78 \%$ of patients who had a preoperative radiology department neck ultrasound, and $86 \%$ of patients with a preoperative endocrinology department ultrasound. There was no correlation between the preoperative laboratory values of calcium and PTH with the scan findings based on our data. Conclusion: Our results showed a high degree of complete concordance between the usual imaging modalities and surgical findings.

(C) 2022 The Author(s).

Published by S. Karger AG, Basel

\section{Introduction}

Primary hyperparathyroidism is a relatively common endocrine disorder, with a solitary parathyroid adenoma responsible for $80 \%-85 \%$ of all cases [1]. It can also present as parathyroid hyperplasia (10\%), multiple adenomas (4\%), and carcinoma (1\%) [2]. 
Table 1. Patient demographics and preoperative clinical findings

\begin{tabular}{lll}
\hline & & $N=59$ \\
\hline Gender, \% & Female & 75 \\
& Male & 25 \\
\hline Age, years & Mean & $52.59 \pm 13.6$ \\
& Range & $16-84$ \\
\hline Nationality, \% & Emirati & 68 \\
& Other Arab & 19 \\
& Non-Arab & 13 \\
\hline Preoperative symptoms (polyuria, & Symptomatic & 48 \\
polydipsia, flank pain and abdominal & Asymptomatic & 52 \\
pain), \% & & \\
\hline Preoperative complications: Kidney & Renal stones & 34 \\
ultrasound findings, \% & Medullary nephrocalcinosis & 6 \\
\hline Preoperative complications: BMD & Normal BMD & 19 \\
findings, \% & Osteopenia & 51 \\
& Osteoporosis & 30 \\
\hline
\end{tabular}

$\mathrm{BMD}$, bone mineral densitometry.
Most patients are either asymptomatic or have vague nonspecific symptoms. The disease is usually found on routine serum calcium measurements. However, approximately one-third of the patients usually become symptomatic over a 15-year period [3].

Parathyroidectomy has evolved significantly over the past decades. A major 4 glands neck exploration and intraoperative palpation in attempt to identify and resect the parathyroid adenoma has changed to a minimally invasive procedure [4-6].

Preoperative imaging could decrease the surgical time and dissection necessary for localization and excision of abnormal parathyroid tissue and might have several benefits, including shorter operation and anesthesia times, decreased postoperative morbidity and decrease in neck scar [7].

Although revision parathyroid surgery is often successful, there may be a substantially increased risk of morbidity due to previous scarring and anatomic variation caused by the previous operation [8]. Therefore, preoperative planning is important to localize the parathyroid glands.

Preoperative planning and localization imaging studies typically include high-resolution ultrasonography (sensitivity, 21\%), magnetic resonance imaging scanning, computerized tomography scanning, technetium $(99 \mathrm{mTc})$ sestamibi imaging (sensitivity, 54\%), and four-dimensional computerized tomography scanning (sensitivity, 88\%) [9] .
Preoperative localization of hyper-functioning parathyroid tissue in patients with primary hyperparathyroidism has been a longstanding diagnostic challenge. In combination, these methods may help localize and guide the surgical approach. While these imaging modalities help localize parathyroid abnormalities, cases still exist where the parathyroid gland is difficult to find intraoperatively.

The study aims to appraise surgical cure in scan positive, scan negative or inconclusive studies in patients diagnosed with primary hyperparathyroidism attending a Dubai hospital. This study also aims to analyze the prevalence of false negative scans that can complicate surgical procedure and outcome. It will also directly compare the neck ultrasound finding to PTH scan-Tc99m/MIBI.

\section{Materials and Methods}

This was a retrospective study conducted in Dubai Hospital, a government tertiary care hospital in the emirate of Dubai, the UAE. We reviewed the electronic medical records and files of all patients with a diagnosis of primary hyperparathyroidism between 1st January 2014 and 31st December 2018 attending the adult endocrinology clinic. The study took place over 1 year.

To qualify for this study, patients were required to have biochemical evidence of primary hyperparathyroidism (inappropriate elevation of serum parathyroid hormone (PTH) levels, combined with elevation of serum calcium concentration). Both female and male patients above age $>13$ years with no history of previous neck surgery and no history of chronic kidney disease were included in the study. 


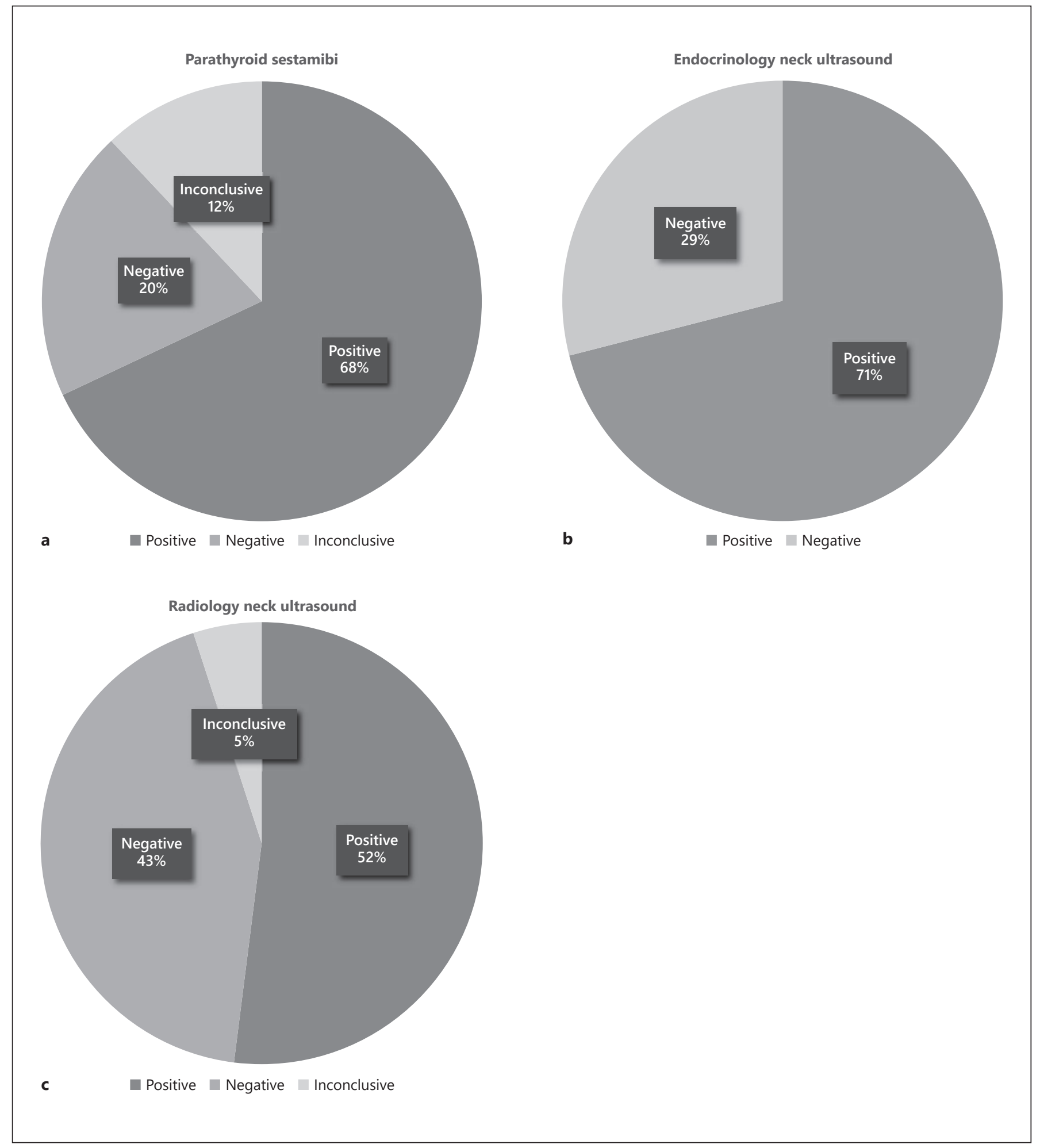

Fig. 1. Findings of preoperative imaging studies. a Parathyroid sestamibi. b Endocrinology neck ultrasound. c Radiology neck ultrasound. 


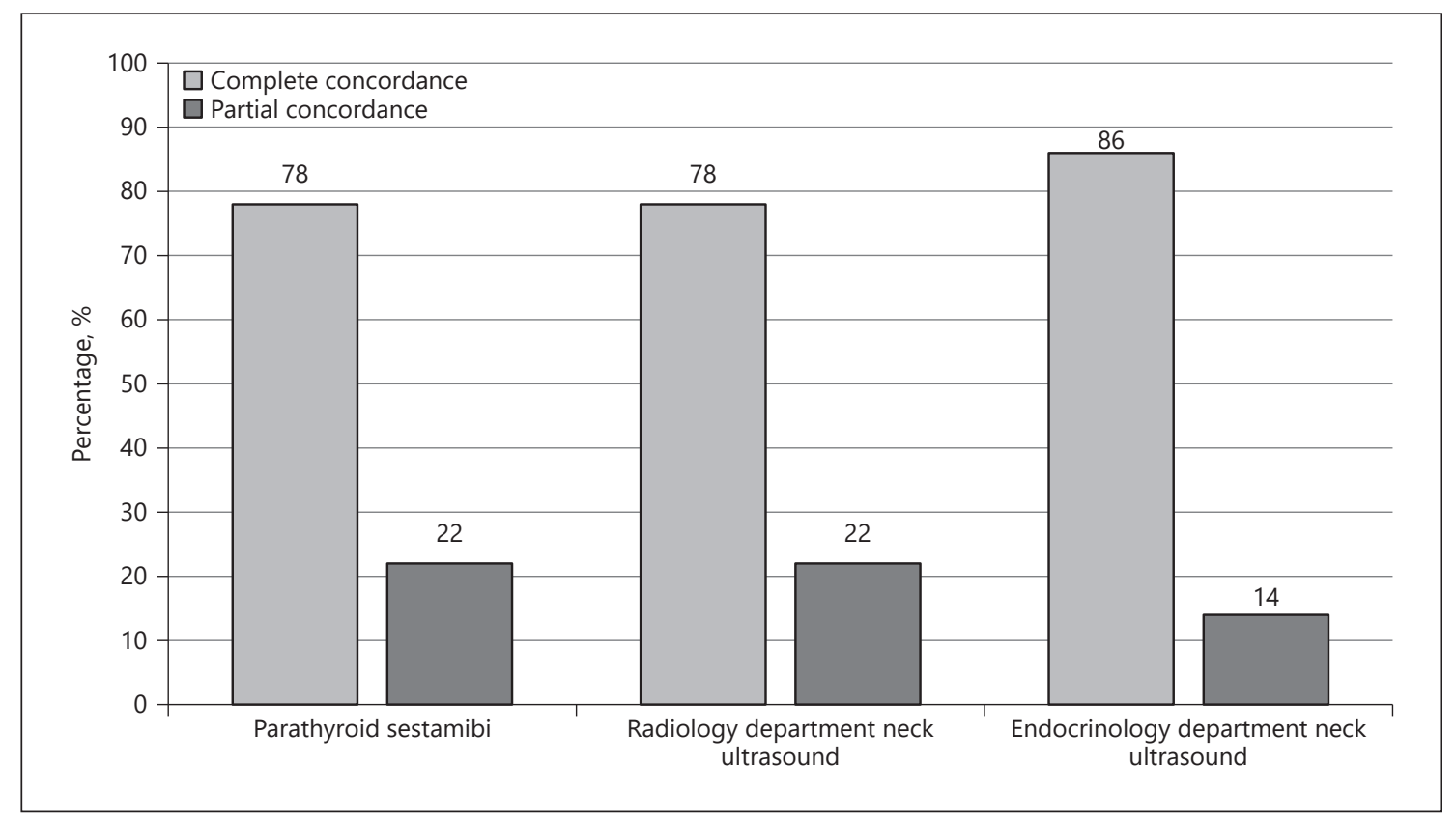

Fig. 2. Concordance of preoperative imaging report of parathyroid site with postoperative anatomical location.

For all patients, data were collected in a self-developed form. Later, data were transformed to an Excel sheet. The form included demographic data, preoperative corrected serum calcium level, preoperative intact PTH level, reported symptoms of hypercalcemia, radiological evidence of kidney damage, bone mineral densitometry results, diagnostic localizing radiological investigation, postoperative calcium level, and pathology finding where available.

Most patients underwent a parathyroid sestamibi scan and an ultrasound neck, either in the radiology department or both with radiology and endocrinology. Endocrinology departmental scans are usually performed in those cases who have either inconclusive results from nuclear medicine or radiology. No other preoperative localization studies were performed. The result was scored as positive, inconclusive, or negative based on the demonstration of uptake on sestamibi and finding of an adenoma on ultrasound. The number and sites of uptake were recorded. Only patients who had a parathyroidectomy were included in the analysis. Parathyroid sestamibi scan and neck ultrasound results were compared to the surgical and histopathological findings. Data analysis was carried out using the Statistical Package for Social Sciences version 24 (SPSS Inc., Chicago, IL, USA) looking at the descriptive analysis as well as $\chi^{2}$ analysis for the correlation of preoperative laboratory value ranges of calcium and PTH with imaging findings.

\section{Results}

This study included $n=59$ patients. Almost threequarters were female (74.6\%). The age ranged between 16 and 84 years with a mean age of 52.59 years $(S D=13.6)$ and with a majority being Emirati nationals (68\%). De- tails of the preoperative reports of symptoms related to hypercalcemia and associated complications are highlighted in Table 1.

\section{Imaging Results}

Preoperative imaging studies done included 50 patients who underwent a parathyroid sestamibi study, 42 who had a radiology department neck ultrasound, and 17 patients who required an endocrinology department neck ultrasound. The findings of the imaging studies are shown in Figure 1. False negative scans were 20\% with parathyroid sestamibi, 29\% with ultrasound scans performed at the endocrinology department, and $43 \%$ with ultrasound scans performed at the radiology department. Although endocrinologist-operated ultrasound scans had more false negatives than sestamibi imaging, it had no inconclusive reports and more confirmed positive findings.

The concordance between preoperative localization studies and the surgical and histopathological findings was analyzed. Complete concordance was defined as correct preoperative identification of the exact gland involved (both laterality and whether it is superior or inferior). Partial concordance is for those with only laterality documented (see Fig. 2). Of note, there were no recorded cases of mismatch of location of adenomas between imaging and location during surgery. 
Table 2. Change in serum calcium and PTH levels
Median [IQR], reference range $8.9-10.2 \mathrm{mg} / \mathrm{dL}$

$11.3[1.4]$

$9.1[0.3]$

Median [IQR], reference range $6-29 \mathrm{pg} / \mathrm{mL}$

$61.5[50]$

$20[13.5]$

Postoperative PTH

(3 months after surgery)

\section{Biochemical Results}

Preoperative serum calcium levels had a median of 11.3 $\mathrm{mg} / \mathrm{dL}$ (IQR 1.4) (normal range, $8.9-10.2 \mathrm{mg} / \mathrm{dL}$ ). Preoperative intact serum PTH levels had a median of $61.5 \mathrm{pg} /$ $\mathrm{mL}$ (IQR 50) (normal range, 5.9-59 pg/mL). Male patients had a slightly higher initial level of calcium, median of 12.6 (IQR 3.95) compared to female patients, median 11.35 $\mathrm{mg} / \mathrm{dL}$ (IQR 1.125). This was also true for parathyroid levels, median of $101 \mathrm{pg} / \mathrm{mL}$ (IQR 86) in males and median of $56 \mathrm{pg} / \mathrm{mL}$ (IQR 33.75) in females. There was no correlation between the preoperative laboratory values of calcium and PTH with the scan findings based on our data.

A majority of patients who underwent a parathyroidectomy were cured with a median postoperative calcium and PTH value within normal reference range (see Table 2,3 ). However, there were a notable number of patients (17.2\%) who had hypocalcemia within the first 3 months postoperatively. $10.3 \%$ of patients had persistent hyperparathyroidism after surgery.

\section{Discussion}

Primary hyperparathyroidism is a common endocrine disorder which has well-established treatment guidelines, with surgical excision of parathyroid adenomas recommended in young patients and those with symptoms or complications related to hypercalcemia [10-12]. For those patients who require a parathyroidectomy, preoperative localization studies are beneficial in obtaining a curative outcome by guiding the surgeon as to the laterality of the gland and enabling minimally invasive surgery with a reduced rate of surgical complications. The demographic profile of our patients was similar to that of patients with hyperparathyroidism described regionally, with a large representation of females in the 4 th and 5 th decades of their life $[13,14]$.

Our study has shown that preoperative imaging at our institution is sensitive and has a low discordance rate with
Table 3. Percentage of patients in normal reference range of calcium and PTH pre and postoperatively

\begin{tabular}{llll}
\hline & $\begin{array}{l}\text { Patients } \\
\text { within normal } \\
\text { range, \% }\end{array}$ & $\begin{array}{l}\text { Patients } \\
\text { above normal } \\
\text { range, \% }\end{array}$ & $\begin{array}{l}\text { Patients } \\
\text { below normal } \\
\text { range, \% }\end{array}$ \\
\hline $\begin{array}{l}\text { Preoperative calcium } \\
\text { Postoperative calcium }\end{array}$ & 3.8 & 96.2 & 0 \\
Preoperative PTH & 79.3 & 3.4 & 17.2 \\
Postoperative PTH & 86.2 & 96.3 & 0 \\
\hline
\end{tabular}

postoperative findings. Most patients who underwent parathyroidectomy achieved a mean calcium and PTH level in the normal range. This is consistent with findings from similar studies done regionally. Al-Kurd et al. [15] reported a $97.5 \%$ overall cure rate for 398 patients with primary hyperparathyroidism who underwent parathyroidectomy at a center in Jerusalem. Their results showed that patients who had negative preoperative imaging had a high cure rate of $80 \%$, but it was still notably less than those with localized adenomas. Their study also reported better lateralization of adenomas preoperatively when an experienced surgeon performed sonography compared to findings from radiology department neck ultrasounds and sestamibi scans [15]. We report similar findings from our own study whereby endocrinologists lateralized the adenoma in $71 \%$ of the scans, while a sestamibi was positive in $68 \%$ of scans performed, and radiology department scans were positive in $52 \%$. The fact that many of the patients at our center had both a sestamibi and an ultrasound performed may have helped in ensuring a surgical cure, as it has been shown that multimodal preoperative imaging increases the sensitivity rate in detecting parathyroid adenomas $[16,17]$. Kaur et al. [18] reported that preoperative neck sonography was more sensitive than sestamibi scanning.

The findings above are despite the limitation that the surgeon at our institution does not have access to $(99 \mathrm{~m})$ Tc-sestamibi radioguided surgery or a rapid intraopera- 
tive PTH assay $[19,20]$. This adds to the value of preoperative imaging for localization.

It is interesting to note that we did not find a significant correlation between preoperative serum calcium and PTH levels and positive sestamibi or ultrasound scan findings. A positive correlation had been reported in several other studies [21, 22]. Hung et al. [23] found in their study that when PTH levels exceeded $200 \mathrm{pg} / \mathrm{mL}$, the diagnostic sensitivity of preoperative sestamibi imaging reached $100 \%$ in primary hyperparathyroidism.

We acknowledge the limitations of the study in its small sample size and retrospective data collection. However, there are no other similar studies done within our country.

\section{Conclusion}

Preoperative imaging using Tc99m-sestamibi scans and neck sonography for localization of parathyroid adenomas at our institution is sensitive with no discordance between imaging and postoperative findings. We have a high surgical cure rate with a significant percentage of patients obtaining serum calcium and PTH levels in the normal reference range 3 months postoperatively. Provision of a specialist service in neck sonography may help in detecting inconclusive cases preoperatively.

\section{Acknowledgment}

The authors would like to thank the Dubai Hospital Radiology and General Surgery departments for their contribution.

\section{Statement of Ethics}

This study and the informed consent of participants were approved by the board of the Dubai Scientific Research Ethics Committee(DSREC),DubaiHealthAuthority(Ref.DSREC-06/2019_13) on 06/AUG/2019. The research complies with the guidelines for human studies in accordance with the World Medical Association Declaration of Helsinki.

\section{Conflict of Interest Statement}

None of the authors have a conflict of interest regarding this manuscript.

\section{Funding Sources}

This research did not receive any specific grant from any funding agency in the public, commercial, or not-for-profit sector.

\section{Author Contributions}

B.A.: study lead and writing, M.A.A: data analysis and writing, F.A.: data collection, S.R.: data collection, F.A.A: study supervision, and F.R.: study design and supervision.

\section{Data Availability Statement}

The data that support the findings of this study are not publicly available due to their containing information that could compromise the privacy of research participants but are available from the corresponding author (M.A.A.) upon reasonable request.

\section{References}

1 Heath H 3rd, Hodgson SF, Kennedy MA. Primary hyperparathyroidism. Incidence, morbidity, and potential economic impact in a community. N Engl J Med. 1980;302(4):189-93.

2 Carlson D. Parathyroid pathology: hyperparathyroidism and parathyroid tumors. Arch Pathol Lab Med. 2010;134(11):1639-44.

3 Rubin MR, Bilezikian JP, McMahon DJ, Jacobs T, Shane E, Siris E, et al. The natural history of primary hyperparathyroidism with or without parathyroid surgery after 15 years. J Clin Endocrinol Metab. 2008;93(9):3462-70.

4 Greene AB, Butler RS, McIntyre S, Barbosa GF, Mitchell J, Berber E, et al. National trends in parathyroid surgery from 1998 to 2008 : a decade of change. J Am Coll Surg. 2009; 209(3):332-43

5 Udelsman R, Akerstrom G, Biagini C, Duh QY, Miccoli P, Niederle B, et al. The surgical management of asymptomatic primary hy- perparathyroidism: proceedings of the fourth international workshop. J Clin Endocrinol Metab. 2014;99(10):3595-606.

6 Henry JF, Sebag F, Cherenko M, Ippolito G, Taieb D, Vaillant J. Endoscopic parathyroidectomy: why and when? World J Surg. 2008; 32(11):2509-15.

7 Okerlund MD, Sheldon K, Corpuz S, O'Connell W, Faulkner D, Clark O, et al. A new method with high sensitivity and specificity for localization of abnormal parathyroid glands. Ann Surg. 1984;200(3):381-8.

8 Thompson GB, Grant CS, Perrier ND, Harman R, Hodgson SF, Ilstrup D, et al. Reoperative parathyroid surgery in the era of sestamibi scanning and intraoperative parathyroid hormone monitoring. Arch Surg. 1999; 134(7):699-704; discussion704-5.

9 Mortenson MM, Evans DB, Lee JE, Hunter GJ, Shellingerhout D, Vu T, et al. Parathyroid exploration in the reoperative neck: improved preoperative localization with $4 \mathrm{D}$-computed tomography. J Am Coll Surg. 2008;206(5): 888-95; discussion 95-6.

10 National Institute for Health and Care Excellence. Hyperparathyroidism (primary): diagnosis, assessment and initial management. NICE Guideline. 2019; NG132.

11 Wilhelm SM, Wang TS, Ruan DT, Lee JA, Asa SL, Duh Q-Y, et al. The American Association of endocrine surgeons guidelines for definitive management of primary hyperparathyroidism. JAMA Surgery. 2016; 151(10):959.

12 Khan AA, Hanley DA, Rizzoli R, Bollerslev J, Young JEM, Rejnmark L, et al. Primary hyperparathyroidism: review and recommendations on evaluation, diagnosis, and management. A Canadian and international consensus. Osteoporos Int. 2017;28(1):1-19. 
13 Al-Jawad M, Rashid AK, Narayan KA. Primary hyperparathyroidism in Saudi Arabia: a review of 46 cases. Med J Malaysia. 2007;62(4): $282-5$.

14 Al-Thani H, El-Matbouly M, Al-Sulaiti M, Asim M, Majzoub A, Tabeb A, et al. Management and outcomes of hyperparathyroidism: a case series from a single institution over two decades. Ther Clin Risk Manag. 2018;14: 1337-45.

15 Al-Kurd A, Levit B, Assaly M, Mizrahi I, Mazeh H, Mekel M. Preoperative localization modalities in primary hyperparathyroidism: Correlation with postoperative cure. Surgery. 2018.

16 Patel SG, Saunders ND, Jamshed S, Weber CJ, Sharma J. Multimodal preoperative localization improves outcomes in reoperative parathyroidectomy: a 25-year surgical experience. Am Surg. 2019;85(9):939-43.
17 El-Hady HA, Radwan HS. Focused parathyroidectomy for single parathyroid adenoma: a clinical account of 20 patients. Electron Physician. 2018;10(6):6974-80.

18 Kaur P, Gattani R, Singhal AA, Sarin D, Arora SK, Mithal A. Impact of preoperative imaging on surgical approach for primary hyperparathyroidism: data from single institution in India. Indian J Endocrinol Metab. 2016; 20(5):625-30.

19 Rubello D, Pelizzo MR, Boni G, Schiavo R, Vaggelli L, Villa G, et al. Radioguided surgery of primary hyperparathyroidism using the low-dose $99 \mathrm{mTc}$-sestamibi protocol: multiinstitutional experience from the Italian Study Group on Radioguided Surgery and Immunoscintigraphy (GISCRIS). J Nucl Med. 2005; 46(2):220-6.

20 Vignali E, Picone A, Materazzi G, Steffe S, Berti $\mathrm{P}$, Cianferotti L, et al. A quick intraoperative parathyroid hormone assay in the surgical management of patients with primary hyperparathyroidism: a Study of 206 Consecutive cases. Eur J Endocrinol. 2002;146(6):783-8.
21 Stawicki SP, El Chaar M, Baillie DR, Jaik NP, Estrada FP. Correlations between biochemical testing, pathology findings and preoperative sestamibi scans: a retrospective study of the minimally invasive radioguided parathyroidectomy (MIRP) approach. Nucl Med Rev Cent East Eur. 2007;10(2):82-6.

22 Dugonjic S, Sisic M, Radulovic M, Ajdinovic B. Positive $(99 \mathrm{~m}) \mathrm{Tc}-\mathrm{MIBI}$ and the subtraction parathyroid scan are related to intact parathyroid hormone but not to total plasma calcium in primary hyperparathyroidism. Hell J Nucl Med. 2017;20(1):46-50.

23 Hung GU, Wang SJ, Lin WY. Tc-99m MIBI parathyroid scintigraphy and intact parathyroid hormone levels in hyperparathyroidism. Clin Nucl Med. 2003;28(3):180-5. 